\title{
Local anaesthetic resistance in a redhead parturient presenting for a prophylactic cervical cerclage: a case report.
}

Kalopita $\mathrm{K}^{1}$, Loukeri $\mathrm{A}^{1}$, Stamatakis $\mathrm{E}^{1}$, Skandalou $\mathrm{V}^{1}$, Antsaklis $\mathrm{P}^{2}$, Valsamidis $\mathrm{D}^{1}$.

1Department of Anaesthesiology and Pain Medicine,

"Alexandra" General Hospital of Athens, Greece.

${ }^{2}$ First Department of Obstetrics and Gynaecology, "Alexandra" General Hospital, National and Kapodistrian University of Athens, Greece.

\section{Background}

Although failed regional anesthesia is mostly attributed to technical failure, we report a case of local anesthetic (LA) resistance possibly due to voltage-gated sodium channellopathy.

\section{Case Report}

A 26-year-old redhead gravida 2, para 1 (15 weeks of gestation) presented for elective placement of cervical cerclage. A single-shot spinal in the left lateral position was decided at $\mathrm{L}_{3-4}$ interspace. Noticeably, the patient failed to achieve adequate skin anaesthesia despite repetitive doses of lidocaine $2 \%$. Free flow of cerebrospinal fluid without aspiration was obtained on first attempt and a spinal injection of $2.3 \mathrm{ml}$ of $0.75 \%$ ropivacaine with $15 \mathrm{mcg}$ of fentanyl was ultimately performed. Ten minutes later, she reported no sensory or motor blockade. A second attempt of the same technique and dose was performed at $\mathrm{L}_{2-3}$ interspace, taking into consideration the possibility of a high sensory block along with hemodynamic instability. Ten minutes after the second attempt, the patient was asked if she felt any difference compared to before; warmth in her feet was reported but no sensory or motor block. The decision was made to proceed with general anesthesia. On questioning, the patient described repeated failures of LAs during her previous caeserean delivery, while she and her mother reported having insufficient anaesthesia during dental procedures.

\section{Discussion}

Inherited channelopathies due to genetic variations in voltage-gated sodium channels, the main site of action of LAs, should not be ruled out when confronting a failed regional anaesthetic technique.

\section{Conclusion}

Our red-haired parturient may be more resistant to LAs due to various mutations of melanocortin receptors as literature suggests.

\section{References}

1. Leconte D, Lemarchand R, Petitjean C, Gentili ME. Repeated failure with regional blocks: Technical problem or resistance to local anaesthetics? Anaesth Crit Care Pain Med. 2017 Dec;36(6):407.

2. Kavlock R, Ting PH. Local anesthetic resistance in a pregnant patient with lumbosacral plexopathy. BMC Anesthesiol. 2004 Jan 16; 4(1):1.

3. Liem EB, Joiner TV, Tsueda K, Sessler DI. Increased sensitivity to thermal pain and reduced subcutaneous lidocaine efficacy in redheads. Anesthesiology.

2005 Mar; 102(3):509-14.

4. Clendenen N, Cannon AD, Porter S, Robards CB, Parker AS, Clendenen SR.

Whole-exome sequencing of a family with local anesthetic resistance. Minerva Anestesiol. 2016 Oct; 82(10):1089-1097. 